NBER WORKING PAPER SERIES

\title{
BUBBLES AND CAPITAL FLOWS
}

\author{
Jaume Ventura
}

Working Paper 9304

http://www.nber.org/papers/w9304

\author{
NATIONAL BUREAU OF ECONOMIC RESEARCH \\ 1050 Massachusetts Avenue \\ Cambridge, MA 02138 \\ October 2002
}

Comments are welcome at jaume@mit.edu or jaume.ventura@crei.upf.es. I thank Pol Antràs for providing excellent research assistance. I am also grateful to the members of the Faculty Macro Lunch at MIT for their useful comments. Of course, none of them is responsible for any error or omission in the paper. The views expressed herein are those of the authors and not necessarily those of the National Bureau of Economic Research.

(C) 2002 by Jaume Ventura. All rights reserved. Short sections of text, not to exceed two paragraphs, may be quoted without explicit permission provided that full credit, including $\odot$ notice, is given to the source. 
Bubbles and Capital Flows

Jaume Ventura

NBER Working Paper No. 9304

October 2002

JEL No. F15, F36, F43

\begin{abstract}
$\underline{\text { ABSTRACT }}$
This paper presents a stylized model of international trade and asset price bubbles. Its central insight is that bubbles tend to appear and expand in countries where productivity is low relative to the rest of the world. These bubbles absorb local savings, eliminating inefficient investments and liberating resources that are in part used to invest in high productivity countries. Through this channel, bubbles act as a substitute for international capital flows, improving the international allocation of investment and reducing rate-of-return differentials across countries. This view of asset price bubbles has important implications for the way we think about economic growth and fluctuations. It also provides a simple account of some real world phenomenae that have been difficult to model before, such as the recurrence and depth of financial crises or their puzzling tendency to propagate across countries.
\end{abstract}

\author{
Jaume Ventura \\ Department of Economics \\ MIT \\ 50 Memorial Drive \\ Cambridge, MA 02139 \\ and NBER \\ jaume@mit.edu
}


This paper presents a stylized model of international trade and asset price bubbles. ${ }^{1}$ Its central insight is that bubbles tend to appear and expand in countries where productivity is low relative to the rest of the world. These bubbles absorb local savings, eliminating inefficient investments and liberating resources that are in part used to invest in high productivity countries. Through this channel, bubbles act as a substitute for international capital flows, improving the international allocation of investment and reducing rate-of-return differentials across countries. This view of asset price bubbles has important implications for the way we think about economic growth and fluctuations. It also provides a simple account of some real world phenomenae that have been difficult to model before, such as the recurrence and depth of financial crises or their puzzling tendency to propagate across countries.

Tirole [1985] has argued that markets create asset price bubbles to eliminate inefficient investments. ${ }^{2}$ His argument goes as follows: Consider an economy where the growth rate exceeds the rate of return to capital. In this economy, a bubble can create its own demand without outgrowing savings by offering a rate of price appreciation above the rate of return but below the growth rate. The bubble absorbs part of the economy's savings, crowding out investment and reducing the capital stock and output. Since the resources devoted to investment (roughly growth times the capital stock) exceed the resources obtained from such activity (roughly the rate of return times the capital stock), the bubble raises consumption and improves welfare. The key insight of Tirole's theory is that the bubble takes away resources from inefficient investors and puts them in the hands of consumers.

An implicit assumption in Tirole's argument is that all investors face the same rate of return. Assume instead that, as a result of frictions in financial markets, the economy contains efficient investors that enjoy rates of return in excess of the growth

\footnotetext{
${ }^{1}$ By a bubble or asset price bubble, I refer to the difference between an asset price and the net present value of its dividend flow or fundamental value.

${ }^{2}$ Tirole's paper builds on the path-breaking work of Samuelson [1958], who was the first to note that useless assets might be valued in a competitive economy and that this would be Pareto improving.
} 
rate, and also inefficient investors that do not. In this economy, a bubble can create its own demand within the group of inefficient investors without outgrowing their savings by offering a rate of price appreciation above their rate of return but below the growth rate. The bubble crowds out inefficient investments and liberates resources that can be used not only to raise consumption, but also to increase efficient investments. Through this channel, the bubble can now lead to an increase in the capital stock and output. Since inefficient investors devote more resources to investment than they obtain from it, the bubble still raises welfare. The key insight now is that the bubble takes away resources from inefficient investors and puts them in the hands of both consumers and efficient investors.

The goal of this paper is to examine the consequences of this view of asset price bubbles for the theories of economic growth and fluctuations. To do this, I keep two maintained hypotheses throughout the paper. The first one is that international goods markets are sufficiently integrated that long-run rates of economic growth are positively linked across countries. This implies that countries that save more and have better technologies and policies are richer but do not grow faster. ${ }^{3}$ The second hypothesis is that international financial markets have limited ability to arbitrage cross-country differences in rates of return. This might be due to a variety of frictions such as policy-induced barriers, transaction costs, information asymmetries and sovereign risk. ${ }^{4}$ If trade in goods ensures that all countries share the same long-run rate of economic growth while frictions in asset trade allow countries to have different rates of return, asset price bubbles naturally arise in those countries where the rate of return is below the common or world growth rate. ${ }^{5}$

\footnotetext{
${ }^{3}$ Leaving a few miracles and disasters aside, there is ample evidence in support of this view. Despite large cross-country differences in economic policies, saving rates and technology, the world income distribution has been relatively stable in the second half of the twentieth century. Howitt [2000] has argued that this stability might be due to technology spillovers, while Acemoglu and I [2002] have argued that it might be due to terms-of-trade effects. Through any of these channels, countries with bad characteristics are able to grow fast and keep up with the rest of the world.

${ }^{4}$ These frictions do not preclude all international capital flows, although the latter are much smaller than what theories based on frictionless markets predict. See Kraay et al. [2000] for a review of the evidence. ${ }^{5}$ In an influential paper, Abel et al. [1989] noticed that the capital share exceeds investment in industrial countries. Since this implies that the average rate of return is above the growth rate, many have used
} 
To study the implications of this observation, I construct a stylized world equilibrium model in which the cost of trading goods is negligible while the cost of trading assets is prohibitive. This is a crude but effective way to capture the two maintained hypotheses discussed above. The model has equilibria with bubbles, in addition to the bubbleless equilibrium that we always take for granted. These are country bubbles, since they can be sold only within the country. ${ }^{6}$ Bubbles appear in countries with low productivity, eliminating domestic investment and raising domestic consumption. This shift in demand lowers the price of investment goods relative to consumption goods all over the world, raising investment in countries with high productivity. Since the transfer of resources from low- to high-productivity countries is done via prices and without any actual or recorded capital flow, this could be aptly described as a theory of capital flows with zero current accounts.

Since bubbles act as a substitute for international capital flows, many of their effects are akin to those that one would expect from financial integration. By improving the average efficiency of investment, asset price bubbles tend to raise the world growth rate. By shifting investments towards countries with high productivity, asset price bubbles tend to make the world economy more sensitive to shocks in these countries and less sensitive to shocks in other countries. By providing lowproductivity countries with a better savings vehicle, asset price bubbles also tend to improve the world income distribution. By expanding at the end of booms and contracting at the end of recessions, bubbles tend to amplify the effects of productivity shocks on investment while dampening their effects on consumption. All of these effects, which are typically associated with financial integration, arise here as

this observation to question the empirical validity of Tirole's model. But this conclusion rests on the assumption that financial markets are frictionless. Even if the average rate of return exceeds the growth rate, the economy might contain pockets of investors with low rates of returns that are willing to buy a bubble. Hence it is not possible in general to rule out the presence of bubbles by comparing the aggregate capital share and investment.

6 In Ventura [2002], I consider the case in which financial markets are well integrated in the sense that domestic and international transactions are subject to the same sort of frictions. In this case, bubbles are traded across countries and I refer to them as global bubbles. 
the sole result of asset price bubbles since capital flows are not possible and trade is always balanced by assumption.

Bubbles also have some effects that are different from those that one would expect from financial integration. For instance, domestic and foreign shocks lead to movements in the size of the bubble that generate potentially large wealth effects. Through this channel, the presence of bubbles magnifies the effects of productivity and other shocks on aggregate activity. Another effect of bubbles is to open the door to shocks to expectations as a new source of macroeconomic fluctuations. Bubbles are inherently unstable, since they arise in environments where agents need to coordinate to one among a variety of possible equilibria. Since bubbles magnify the effects of productivity shocks and open the door to expectational shocks, low productivity countries that have large bubbles tend to be more volatile than high productivity countries that have small bubbles. But the relationship between volatility and productivity is nonlinear. Countries with intermediate levels of productivity tend to have smaller but more volatile bubbles. In particular, I find that in these countries external shocks generate movements in the size of their bubbles that have potentially large wealth effects. This observation can be used to provide a theoretical justification to the notion that middle-income countries are very vulnerable to small economic fluctuations in high-income countries. It can also be used as key building block in an attempt to sketch a theory of the international contagion of financial crises.

The paper is organized as follows: Section one presents a stylized model of trade and growth and describes the world equilibrium without bubbles. Section two shows that there are additional world equilibria with bubbles and formally describes them. Sections three to seven present five examples designed to illustrate the macroeconomic effects of bubbles. The first two emphasize the role of bubbles as a substitute for international capital flows. The remaining three deal with the concepts of financial fragility, vulnerability to external shocks and contagion. Section eight concludes. 


\section{A Productivity-Based View of the Growth Process}

In this section I present a simple model of trade and growth that will serve as a tool or vehicle to study the conditions under which asset price bubbles can exist and their macroeconomic effects. The model has some unrealistic features such as the prediction that factor prices are equalized across countries or the assumption that the law of one price applies to all goods. These aspects of the model are not important however for the results of this paper, and have been chosen only to streamline the discussion. The two critical features of the model have already been discussed in the introduction: while trade in goods ensures that long-run rates of economic growth are equalized across countries, frictions in asset trade preclude the elimination of rate-ofreturn differentials across countries. There are various models of trade and growth that share these two critical features without predicting that goods and factor prices are equalized across countries. For instance, Acemoglu and I [2002] wrote a model with these characteristics recently.

Consider a world economy with $\mathrm{J}$ countries, indexed by $\mathrm{j}=1,2, \ldots, \mathrm{J}$. There are two factors of production: labor and capital, and they are used in the production of two intermediates: K- and L-products. These intermediates are in turn used to produce two final goods: consumption and investment. The costs of transporting factors are prohibitive, while the costs of transporting goods are negligible.

In all countries there are competitive firms with access to a common technology to produce intermediates. To produce one unit of the K-product, these firms require one unit of capital. To produce one unit of the L-product, they need one unit of labor. Since final goods production only requires intermediates, full employment of factors implies that both intermediates are produced in all countries. Perfect competition ensures that the rental and the wage are equal to the prices of $\mathrm{K}$ and L-products in all countries, while international trade ensures that the prices of these intermediates are equalized across countries. It follows that factor prices are 
equalized across countries as well. ${ }^{7}$ Define $r_{t}$ and $w_{t}$ as the common rental (or price of $\mathrm{K}$-products) and wage (or price of L-products) at date $\mathrm{t}$.

In all countries there are also competitive firms with access to a common technology to produce final goods. To produce one unit of the consumption good, firms have a Cobb-Douglas technology with a L-product (or labor) share equal to $\alpha$, with $0<\alpha<1$. To produce one unit of the investment good, firms have a technology that requires one unit of the K-product. Since all firms in all countries face the same price of intermediates, the costs of producing final goods are also the same in all countries. Perfect competition then ensures that goods prices equal these production costs:

$$
\begin{aligned}
& 1=r_{t}^{1-\alpha} \cdot w_{t}^{\alpha} \\
& q_{t}=r_{t}
\end{aligned}
$$

where $q_{t}$ is the price of investment and consumption is the numeraire.

The demographic structure of countries is that of a two-period overlapping generations model with constant population. All generations have size one. In each date, a new generation of consumers is born that lives two periods: young and old. The consumers' goal in life is to maximize the expected value of old age consumption. When young, consumers work and save their wage. The only decision in their life is what to do with these savings. When old, consumers use the return to their savings to purchase consumption goods. This formulation is nothing but a stark version of the popular life-cycle model of savings.

\footnotetext{
${ }^{7}$ This result is due to Samuelson [1948] and applies to a wide range of models (See Krugman and Helpman [1985]). What is perhaps surprising here is that factor prices are equalized for any crosscountry distribution of capital-labor ratios. This is a special but very convenient property of this specific production structure that I borrow from Ventura [1997].
} 
In each generation, some of the young create and operate firms that purchase investment goods in their youth and convert them into capital that can be used in their old age. For simplicity, I assume that this entrepreneurial activity requires no effort and that there is enough talent in the country so as to drive the wage of entrepreneurs to zero. The entrepreneurs of country $j$ at date $t$ are capable of producing $\pi_{t+1}^{j}$ units of capital with each investment good. I refer to $\pi_{t+1}^{j}$ as the productivity of country $j$ and assume that it can vary stochastically over time within a support that is strictly positive and bounded above. Let $\mathrm{I}_{t}^{\mathrm{j}}$ and $\mathrm{K}_{\mathrm{t}}^{\mathrm{j}}$ be the investment and capital stock of the country. Assuming that capital fully depreciates in one generation, we have that:

$$
\mathrm{K}_{\mathrm{t}+1}^{\mathrm{j}}=\pi_{\mathrm{t}+1}^{\mathrm{j}} \cdot \cdot_{\mathrm{t}}^{\mathrm{j}}
$$

Given these assumptions, each unit of income invested in country $\mathrm{j}$ yields a rate of return equal to $\frac{r_{t+1} \cdot \pi_{t+1}^{j}}{q_{t}}$. To finance their purchases of investment goods, firms issue shares and sell them in the domestic stock market. After output has been produced and distributed in the form of dividend, the firm has no assets and the value of its shares drops to zero.

A key assumption is that the costs of trading in the domestic stock market are negligible, while the costs of trading in foreign stock markets are prohibitive. This asymmetry in costs could be due to a policy-induced barrier such as prohibitive capital controls, or it could be due to the inability of countries to commit not to expropriate foreign investments. Whatever the reason, the young are forced to invest all of their savings in the domestic stock market, and this implies the following:

$$
\begin{aligned}
& q_{t} \cdot l_{t}^{j}=w_{t} \\
& C_{t}^{j}=r_{t} \cdot K_{t}^{j}
\end{aligned}
$$


Equation (4) states that investment is equal to labor income, since the young save the entire wage. Equation (5) shows that consumption is equal to capital income, since the old have no bequest motive.

Define world averages by omitting the country subscript. For instance, the world average capital stock is $\mathrm{K}_{\mathrm{t}}=\frac{1}{\mathrm{~J}} \cdot \sum_{\mathrm{j}} \mathrm{K}_{\mathrm{t}}^{\mathrm{j}}$. Applying Shepard's lemma to Equations (1) and (2), we find the world average demands for K and L-products as $\frac{1}{r_{t}} \cdot q_{t} \cdot l_{t}+\frac{1-\alpha}{r_{r}} \cdot C_{t}$ and $\frac{\alpha}{w_{t}} \cdot C_{t}$, respectively. Since the average supplies of these products are $\mathrm{K}_{\mathrm{t}}$ and 1 , international commodity markets clear if and only if:

(7) $\quad w_{t}=\alpha \cdot C_{t}$

The competitive equilibrium of this world economy is a set of prices and quantities such that consumers optimize and markets clear. Together with an initial distribution of capital stocks, Equations (1)-(7) provide a complete description of this equilibrium. By Walras' law, one among Equations (4)-(7) is redundant and can be dropped. I show next some properties of this world equilibrium.

Let $R_{t}^{j}$ be the rate of return to the portfolio of country j. Since this portfolio contains only domestic investment, we can use Equations (1), (2) and (7), to find that:

(8) $\quad R_{t}^{j}=g_{t}^{\frac{-\alpha}{1-\alpha}} \cdot \pi_{t}^{j}$

where $g_{t}$ is the growth rate of world consumption, i.e. $g_{t} \equiv \frac{C_{t+1}}{C_{t}}$. Consider the case in which this growth rate is positive. Despite the continuous decline in the rental rate, 
the rate of return remains constant because the price of investment goods also declines at the same rate. This follows from Equation (2) and is a direct consequence of the assumption that only capital is used in the production of investment goods. The idea that there exists a core of capital goods that can be produced using only this same core of capital goods is the basic tenet underlying the linear growth model of Rebelo [1991]. Here we have adopted the extreme AK version of this model in which there is only one capital good in this core.

It follows from Equations (3), (5) and (7) that the world growth rate of consumption is given by:

$$
g_{t}=\alpha \cdot R_{t}
$$

The world growth rate depends positively on $\alpha$ and $R_{t}$. The higher is $\alpha$, the higher is the labor share in income and the higher is world savings. The higher is $R_{t}$, the higher is the average return obtained from these savings. All countries share a common growth rate in the long run. The reason is simple: growth in high-return countries improves the terms of trade of low-return ones and this keeps the world income distribution stable. Since wages are equalized internationally, all countries save the same, and differences in consumption reflect differences in rates of return. To see this, note that Equations (3)-(5) imply that $\frac{C_{t}^{j}}{C_{t}}=\frac{R_{t}^{j}}{R_{t}} .8$

Solving Equations (8) and (9), we obtain this stylized description of the growth process as a function of the exogenously specified productivity processes:

$$
g_{t}=\left(\alpha \cdot \pi_{t}\right)^{1-\alpha}
$$

\footnotetext{
${ }^{8}$ It would be straightforward to introduce labor-augmenting productivities differences across countries as in Ventura [1997]. This would generate cross-country differences in wages and savings.
} 
World growth depends on average productivity, while each country's position in the world distribution of consumption or wealth depends on its relative productivity. This world therefore encapsulates a traditional or productivity-based view of economic growth and fluctuations. This view is reasonable and has the potential to explain some of the most interesting growth experiences, such as the existence of growth miracles or worldwide changes in rates of economic growth. But the productivitybased view is not well suited to explain other real world phenomenae such as the recurrence and depth of financial crises or their puzzling tendency to propagate across countries. A key question is therefore: How can we model these aspects of reality without losing the basic insights of the productivity-based view? A central claim of this paper is that the implicit (and unjustified) assumption that asset prices reflect their fundamental value is the obstacle that stands on the way of doing this. Once we push it aside, it is possible to catch an eye-opening glimpse of what the productivitybased view has been leaving behind.

\section{Country Bubbles}

If $R_{t}^{j}>g_{t}$ for all $j$ and $t$, the world equilibrium described in the previous section is unique. But if $R_{t}^{j}<g_{t}$ for some $j$ and $t$, there might be other equilibria in which useless assets or firms are valued and traded in the stock market. Following standard convention, I refer to these useless assets or firms as pure bubbles. ${ }^{9}$ To be clear, these bubbles are rational since their existence does not rely on the presence of individuals that are incapable of processing publicly available information or that behave in a manner that is inconsistent with the usual axioms of choice theory. In the bubbly equilibria studied here, the old sell bubbles to the young. The later understand

\footnotetext{
${ }^{9}$ The distinction between productive assets and pure bubbles is useful as a theoretical device. However in the real world asset price bubbles sometime seem to appear in productive assets. Olivier [2000] shows how to modify the theory to allow for bubbles that are "attached" to productive assets.
} 
that these bubbles will never deliver a dividend, but they still buy them because they rationally expect a return in the form of price appreciation.

Since the costs of international trade in assets are still prohibitive, bubbles are only traded within the country. That is, they are country bubbles. Let $\mathrm{B}_{\mathrm{t}}^{\mathrm{j}}$ be the size of the bubble in country $j$ at date $t$, i.e. the value of all the useless firms traded in the stock market of country j. This bubble grows according to this process:

$$
B_{t+1}^{j}=\mu_{t+1}^{j} \cdot B_{t}^{j}
$$

where $\mu_{t+1}^{j}$ is the growth rate of the bubble or its rate of price appreciation. Note that $\mu_{t+1}^{j}$ might not be known as of date $t$, since in general the value of the bubble at date $\mathrm{t}+1$ depend on information that is not available at date $\mathrm{t}$. I define a country bubble as an initial value, i.e. $B_{0}^{j}>0$ and a price appreciation process, i.e. $\mu_{t+1}^{j}$ for all $t \geq 0$.

The presence of a bubble enlarges the portfolio choice of the young since they now can choose whether to hold the capital stock, the country bubble, or both. We must therefore replace Equation (4) by this pair:

$$
q_{t} \cdot I_{t}^{j}+B_{t}^{j}=w_{t}
$$

$$
B_{t}^{j}=\left\{\begin{array}{cc}
0 & \text { if } E_{t}\left\{\mu_{t+1}^{j}\right\}<E_{t}\left\{\frac{r_{t+1} \cdot \pi_{t+1}^{j}}{q_{t}}\right\} \\
{\left[0, w_{t}\right]} & \text { if } E_{t}\left\{\mu_{t+1}^{j}\right\}=E_{t}\left\{\frac{r_{t+1} \cdot \pi_{t+1}^{j}}{q_{t}}\right\} \\
w_{t} & \text { if } E_{t}\left\{\mu_{t+1}^{j}\right\}>E_{t}\left\{\frac{r_{t+1} \cdot \pi_{t+1}^{j}}{q_{t}}\right\}
\end{array}\right\}
$$

Equation (12) shows that the young now distribute their savings between the stock of capital and the bubble. Equation (13) describes the choice of country 
portfolio as a function of asset returns. The return to holding a bubble is its growth rate, i.e. $\mu_{t+1}^{j}$; while the return to holding capital is the dividend, i.e. $\frac{r_{t+1} \cdot \pi_{t+1}^{j}}{q_{t}}$. Since the young are risk-neutral, they choose the asset that offers the highest expected return. If both assets offer the same expected return, the young are indifferent between holding capital, the bubble or both.

The presence of the bubble also implies that the consumption of the old is now given by their capital income plus the proceeds of selling the bubble. Therefore, we must replace Equation (5) by:

$$
C_{t}^{j}=r_{t} \cdot K_{t}^{j}+B_{t}^{j}
$$

The rest of the model remains the same. For a given initial distribution of capital stocks, a competitive equilibrium of the world economy consists of a set of country bubbles such that Equations (1)-(3), (6)-(7) and (11)-(14) hold for all possible realizations of the world economy. Once again, by Walras' law we can drop one among Equations (6), (7), (12) and (14). The productivity-based view or bubbleless equilibrium obtains by setting $B_{0}^{j}=0$ for all $j$; and $E_{t}\left\{\mu_{t+1}^{j}\right\}<E_{t}\left\{\frac{r_{t+1} \cdot \pi_{t+1}^{j}}{q_{t}}\right\}$ for all $j$ and t. This equilibrium always exists, as shown in the previous section. But it might not be unique.

Since the country portfolio now might contain the bubble, its rate of return need no longer be equal to the rate of return to capital. Define $b_{t}^{j}$ as the share of the bubble in the country portfolio or savings, i.e. $b_{t}^{j} \equiv \frac{B_{t}^{j}}{q_{t} \cdot \cdot_{t}^{j}+B_{t}^{j}}$. The rate of return to country j's portfolio is now given by: 


$$
R_{t}^{j}=g_{t}^{\frac{-\alpha}{1-\alpha}} \cdot \pi_{t}^{j} \cdot\left(1-b_{t-1}^{j}\right)+\mu_{t}^{j} \cdot b_{t-1}^{j}
$$

A bit of algebra shows that Equation (9) still describes the world growth rate. However, it is not possible to provide a complete description of the growth process as a function of exogenous impulses using Equations (9) and (15) alone. To do so we need to specify exogenously not only the path of productivity, but also how countries coordinate to a particular equilibrium. For instance, the derivation of Equation (10) implicitly assumes that: (i) the bubbleless equilibrium is unique or, alternatively, (ii) all countries coordinate to the bubbleless equilibrium with probability one. Either of these two assumptions or views is sufficient to justify the productivity-based view of the growth process. But they are not the only possibilities.

As a prelude to making assumptions on how countries coordinate to a given equilibrium, it is useful to obtain a simple characterization of all the sets of country bubbles that are feasible in world equilibrium. The following proposition does this:

Proposition \#1: Consider $\mathrm{J}$ sequences $\left\{b_{t}^{j}\right\}_{t=0}^{t=\infty}$ such that $b_{t}^{j} \in[0,1]$ for all $t$ and $j$. The set of country bubbles defined by these sequences is feasible if and only if, for all $\mathrm{j}$ and $t,(C 1) E_{t}\left\{g_{t+1} \cdot \frac{b_{t+1}^{j}}{b_{t}^{j}}\right\} \geq E_{t}\left\{g_{t+1}^{\frac{-\alpha}{1-\alpha}} \cdot \pi_{t}^{j}\right\}$, with $b_{t}^{j}=1$ if the inequality is strict; and (C2) $g_{t+1}=\left(\alpha \cdot \frac{\sum_{j} \pi_{t+1}^{j} \cdot\left(1-b_{t}^{j}\right)}{\left.J-\alpha \cdot \sum b_{t+1}^{j}\right)}\right)^{1-\alpha}$.

The proof simply consists on substituting Equation (11) into (13) and using equilibrium prices to obtain (C1), and to substitute Equation (15) into Equation (9) to obtain (C2). The proposition is useful because it allows us to check whether a proposed set of country bubbles is feasible by solving a small system of equations. 
To develop intuitions about the macroeconomic effects of bubbles, I develop next five examples. Together, they reveal a new and broader view of the growth process in which both productivity and asset price bubbles play central roles, and interact in interesting and somewhat surprising ways. A recurring theme is that bubbles substitute for capital flows and, as a result, their main effects are akin or similar to those of financial integration. Another theme is that movements in the size of bubbles create large wealth shocks. These movements might be driven by shocks to productivity. But the presence of bubbles also opens the door for shocks to expectations to become part of the macroeconomic landscape.

\section{Bubbles as a Substitute for Long-Term Capital Flows}

Assume the world contains infinitely many countries of two types. Half of them have low productivity, i.e. $\pi_{t}^{j}=\pi^{\mathrm{L}}$; while the rest have high productivity, i.e. $\pi_{\mathrm{t}}^{\mathrm{j}}=\pi^{\mathrm{H}}>\pi^{\mathrm{L}}$. The goal of this example is to determine how the presence of bubbles affects both the world growth rate and the distribution of wealth across countries.

It is useful to start by describing the bubbleless equilibrium. It follows from Equations (8) and (9) that in this equilibrium the following applies:

$$
\begin{aligned}
& g=\left(\alpha \cdot \frac{\pi^{\mathrm{L}}+\pi^{\mathrm{H}}}{2}\right)^{1-\alpha} \\
& R^{\mathrm{j}}=g^{\frac{-\alpha}{1-\alpha}} \cdot \pi^{\mathrm{j}}
\end{aligned}
$$

The world growth rate depends only on average productivity, while the crosscountry distribution of rates of return (and consumption or wealth) depends on how 
dispersed this productivity is. As discussed already, this is the essence of the productivity-based view of economic growth.

But this might not be the only equilibrium of this world economy. Consider the possibility that country $\mathrm{j}$ deviates from the others and coordinates to an equilibrium with a stationary bubble, i.e. $b_{t}^{j}=b$ for all $t$. Is this possible? Since the world growth rate is constant and there is no uncertainty, condition $(\mathrm{C} 1)$ for this bubble can be written as follows:

$$
g^{\frac{1}{1-\alpha}} \geq \pi^{\mathrm{j}}
$$

To create its own demand, the bubble must grow at a rate that is no lower than the rate of return to capital, i.e. $\mathrm{g}^{\frac{-\alpha}{1-\alpha}} \cdot \pi^{\mathrm{j}}$. To ensure that it does not outgrow savings, the bubble must grow at a rate that is no higher than the growth rate, i.e. g. Therefore, Equation (19) says that there is room for a bubble in country $j$ if and only if the growth rate exceeds the rate of return to capital. Except for the knife-edge case in which inequality (18) holds strictly, we have that:

$$
b=1
$$

That is, the bubble crowds out all the investment of the country. If country $\mathrm{j}$ is a highproductivity country this bubble is not feasible because condition (18) never holds (To check this, substitute Equation (16) into condition (18) with $\pi^{\mathrm{j}}=\pi^{\mathrm{H}}$ ). If country $\mathrm{j}$ is a lowproductivity country the bubble might be feasible because condition (18) holds for some parameter values. ${ }^{10}$

\footnotetext{
${ }^{10}$ If it has low productivity, country $\mathrm{j}$ might also have any of a continuum of non-stationary bubbles defined by an initial value $b_{0}{ }^{j} \in(0,1]$ and sequence of $b_{t}^{j}$ such that $(C 1)$ holds with strict equality. These bubbles vanish gradually over time and will be ignored in the rest of this paper.
} 
Consider the case in which a fraction $\phi$ of the low productivity countries coordinate to the bubbly equilibrium, while the rest coordinate to the bubbleless one. I refer to $\phi$ as the size of the world bubble. It follows from Equations (9) and (15) that:

$$
\begin{aligned}
& g=\left(\alpha \cdot \frac{(1-\phi) \cdot \pi^{\llcorner}+\pi^{H}}{2-\alpha \cdot \phi}\right)^{1-\alpha} \\
& R^{j}= \begin{cases}g & \text { if } b_{t}^{j}=1 \\
g^{\frac{-\alpha}{1-\alpha}} \cdot \pi^{j} & \text { if } b_{t}^{j}=0\end{cases}
\end{aligned}
$$

Equations (20) and (21) describe the world growth rate and the return to the country portfolios in the bubbly equilibrium. Substituting Equation (20) into condition (18), we find that this equilibrium exists if and only if cross-country dispersion in productivity is sufficiently high, i.e. if $\frac{\pi^{L}}{\pi^{\mathrm{H}}}<\frac{\alpha}{2-\alpha}$. Assume this from now on.

Using Equation (20), it is straightforward to check that the world growth rate increases with the size of the bubble. The key intuition is that the bubble eliminates inefficient investments in low-productivity countries and raises efficient investments in high-productivity ones. An increase of one percent in the world bubble increases consumption (or reduces investment spending) by one percent in countries where average productivity is $\pi^{L}$. This lowers the price of investment goods and raises the wage all over the world. A lower price of investment goods means that each unit of savings buys more investment goods, while a higher wage means that savings increases all over the world. A one percent increase in the world bubble leads to an increase of investment spending of $\alpha$ percent in the rest of the world where average productivity is $\frac{(1-\phi) \cdot \pi^{\mathrm{L}}+\pi^{\mathrm{H}}}{2-\alpha \cdot \phi}$ (See Equations (7) and (12)). Since Equations (18) and (20) ensure that the bubble is feasible if and only if $\pi^{\llcorner}<\alpha \cdot \frac{(1-\phi) \cdot \pi^{\llcorner}+\pi^{H}}{2-\alpha \cdot \phi}$, we have 
that an increase in the size of the bubble increases the world capital stock for a given level of production and this raises the world growth rate. The maximum world growth rate applies in the limit where the bubble is as large as it can be, i.e. $\phi \rightarrow 1$.

Using Equation (21), we also find that the presence of bubbles raises the rate of return of the portfolio of the countries that hold the bubble relative to the rest of the world. This means that these countries move up in the world distribution of consumption and wealth. Since countries that have a bubble also have low productivity, the presence of bubbles tends to reduce rate-of-return differentials and improve the world distribution of consumption and wealth. (Remember that $\frac{C_{t}^{j}}{C_{t}}=\frac{R_{t}^{j}}{R_{t}}$ ). In fact, the most equalitarian distribution applies in the limit when the bubble is as large as it can be, i.e. $\phi \rightarrow 1$.

This example illustrates the role of bubbles as a substitute for long-term capital flows. Since the later are not possible, stock markets generate bubbles as an alternative or second-best mechanism to improve the world allocation of investment. Bubbles arise in low-productivity countries, eliminating inefficient investments and liberating resources that are used in part to increase investment in high-productivity countries. This transfer is made via changes in prices and without actual capital flows, since we have assumed throughout that trade is balanced and current accounts are zero. By increasing the efficiency of world investment, bubbles raise the world growth rate. By reducing rate-of-return differentials across countries, bubbles improve the world income distribution. 


\section{Bubbles as a Substitute for Short-Term Capital Flows}

Consider next a world with infinitely many countries of a single type.

Productivity fluctuates between a high and a low state, i.e. $\pi_{t}^{\mathrm{j}} \in\left\{\pi^{\mathrm{L}}, \pi^{\mathrm{H}}\right\}$ with $\pi^{\mathrm{H}} \geq \pi^{\mathrm{L}}$. I assume that productivity is known before making investments, i.e. $E_{t}\left\{\pi_{t+1}^{j}\right\}=\pi_{t+1}^{j}$. The probability of transitioning from one state to the other is equal to $\lambda$ and is independent across $\mathrm{j}$ and t. The world starts with half of the countries in each state. Since this is the invariant distribution, the proportion of countries in each state is constant over time. The goal of this example is to determine how the presence of bubbles determines the way countries react to productivity shocks.

The bubbleless equilibrium of this world economy is the same as in the previous example, i.e. as described in Equations (16)-(17). The only difference is that now all countries are ex-ante identical and each of them spends half of the time being low-productivity and half of the time being high-productivity. As $\lambda \rightarrow 0$ differences in productivity become permanent and we approach the world we analyzed in the previous subsection.

Consider the possibility that country j deviates from the others and coordinates to an equilibrium with a stationary bubble, i.e. $b_{t}^{j}=b^{H}$ if $\pi_{t}^{j}=\pi^{H}$ and $b_{t}^{j}=b^{L}$ if $\pi_{t}^{j}=\pi^{L}$. In this case, condition (C1) implies the following:

$$
\left[1-\lambda+\lambda \cdot \frac{b^{H}}{b^{L}}\right] \cdot g^{\frac{1}{1-\alpha}} \geq \pi^{L} \quad \text { and } \quad\left[1-\lambda+\lambda \cdot \frac{b^{L}}{b^{H}}\right] \cdot g^{\frac{1}{1-\alpha}} \geq \pi^{H}
$$

Since $\pi^{\mathrm{H}}>\mathrm{g}^{\frac{1}{1-\alpha}}$ the bubble must expand at the end of high productivity periods to create its own demand, i.e. $b_{\mathrm{L}}>b_{H}$. This in turn implies that the bubble must contract at 
the end of low productivity periods. Except for the knife-edge case in which both inequalities hold strictly, it follows from (22) that:

$$
b^{L}=1 \quad b^{H}=\frac{\lambda}{\lambda+\frac{\pi^{H}}{g^{\frac{1}{1-\alpha}}}-1}
$$

Now either all the countries can have the bubble, or none of them can have it. Note also that shocks to productivity generate movements in the bubble. Transitions to the high state lead to contractions of the bubble, while transitions to the low state lead to expansions. Equation (23) shows that the size of these movements is positively related to the world growth rate. The larger is the latter the more attractive is the bubble inside high productivity periods, and the smaller are the expansions at the end of these periods that are required to support the demand for the bubble. Equation (23) also shows that there is a positive relationship between the size of these movements in the bubble and the persistence of shocks. The smaller is the transition probability the lower is the likelihood that the bubble expands and, as a result, the larger are the expansions that are required at the end of high productivity periods.

Consider the case in which a fraction $\phi$ of the countries coordinate to the stationary bubble, while the rest coordinate to the bubbleless equilibrium. ${ }^{11}$ It follows from Equations (9) and (15) that, in this case:

$$
g=\left(\alpha \cdot \frac{(1-\phi) \cdot \pi^{\mathrm{L}}+\left(1-\phi \cdot b^{\mathrm{H}}\right) \cdot \pi^{\mathrm{H}}}{2-\alpha \cdot \phi \cdot\left(1+b^{\mathrm{H}}\right)}\right)^{1-\alpha}
$$

\footnotetext{
${ }^{11}$ Note that now $\phi$ is the fraction of all countries with a bubble, while in the previous example $\phi$ was the fraction of low-productivity countries with a bubble. Since the previous example obtains as the limit in which $\lambda \rightarrow 0$ and $b^{\mathrm{H}} \rightarrow 0$, all the formulas in the previous section are valid under both definitions.
} 


$$
R_{t}^{j}= \begin{cases}g^{\frac{-\alpha}{1-\alpha}} \cdot \pi^{H} \cdot\left(1-b^{H}\right)+g \cdot b^{H} & \text { if } \pi_{t}^{j}=\pi_{t+1}^{j}=\pi^{H} \\ g^{\frac{-\alpha}{1-\alpha}} \cdot \pi^{H} \cdot\left(1-b^{H}\right)+g & \text { if } \pi_{t}^{j}=\pi^{H} \text { and } \pi_{t+1}^{j}=\pi^{L} \\ g & \text { if } \pi_{t}^{\mathrm{j}}=\pi_{t+1}^{\mathrm{j}}=\pi^{\mathrm{L}} \\ g \cdot b^{H} & \text { if } \pi_{t}^{\mathrm{j}}=\pi^{\mathrm{L}} \text { and } \pi_{t+1}^{\mathrm{j}}=\pi^{\mathrm{H}}\end{cases}
$$

where I have used the finding that $b^{L}=1$. Equations (23)-(25) provide a full description of the bubbly equilibrium, if it exists. The latter requires a sufficiently high dispersion of productivities. In fact, it is easy to show that this restriction is more stringent now than in the previous example. Assume that it is satisfied from now on.

The equilibrium values for $b^{\mathrm{H}}$ and $g$ are obtained by crossing Equations (24) and (25). Figure 1 shows how these values depend on $\phi$ and $\lambda$. An increase in the world bubble raises the world growth rate and, for the reasons discussed, it increases the size of the bubble in high productivity countries (compare points A and B). An increase in the transition probability raises the size of the bubble in high productivity countries and, as a result, it reduces efficient investment and lowers the world growth rate (compare points $\mathrm{A}$ and $\mathrm{C}$ ).

In this example the presence of a bubble not only raises the long-run rate of growth, but also affects the nature of economic fluctuations. A first effect of the bubble is hat increases the volatility of investment. In countries that do not have a bubble, investment is not sensitive to domestic productivity and is determined solely by the savings of the young. In countries that do have a bubble, investment fluctuates with domestic productivity. When productivity is high, the bubble contracts and investment expands. When productivity is low, the bubble expands and investment contracts. This is how bubbles break the link between changes in domestic investment and the savings of the young, just as international capital flows would do if they were possible. 
A second effect of the bubble is to create potentially large wealth effects that impact on consumption. In countries without a bubble, consumption fluctuates one-toone with domestic productivity. This is not the case in countries with a bubble, since their consumption depends on both the return to capital and the rate of growth of the bubble. Conditional on being in normal times (i.e. periods in which a country does not transition from one state to the other), countries with a bubble have a smoother consumption process than those without a bubble. The reason is that the rate of return to their portfolio is higher in the low state but lower in the high state. If this were all, we would conclude that the bubble reduces the volatility of consumption just as international capital flows would do in this context if they were possible. But bubbles also generate a source of volatility in consumption that we would not observe in a financially integrated world. During the transitions from one state to the other, the movements in the size of the bubble generate wealth effects that might potentially have a large impact on consumption and welfare. In particular, we have that at the end of high-productivity periods there is a consumption boom, while at the end of lowproductivity periods there is a consumption bust.

This world economy provides another example of how stock markets create bubbles as a substitute for international capital flows. Bubbles expand when the economy transitions to the low productivity state, absorbing savings and eliminating inefficient investments. Bubbles contract when the economy transitions to the high productivity state, releasing savings and making room for efficient investments. These movements in the bubble shift investments from low to high productivity countries, improving the world allocation of investment and reducing rate-of-return differentials across countries. As a result of the movements in the bubble, investment becomes more volatile than what standard models would predict, while consumption becomes smoother in normal times but subject to potentially large wealth shocks associated with expansions and contractions in the bubble. 
Some of the implications of the theory are becoming clear now. The same factors that would generate a capital outflow (i.e. the realization that a high productivity period is ending) generate growth in the bubble as a prelude to a collapse of investment. Conversely, the same factors that would generate a capital inflow (i.e. the realization that a low productivity period is ending) generate a collapse in the bubble as a prelude to an investment boom. Provided that the country always coordinates to the stationary bubble, the movements of the later are therefore closely tied to movements in productivity. But why would the economy always coordinate to the stationary bubble? The answer, of course, is that it does not have to.

\section{Financial Fragility}

Consider the same world as in the previous example, but now assume that all countries coordinate to an equilibrium using a country-specific sunspot variable that says BUBBLE with probability $\phi$ and NO BUBBLE with probability 1- $\phi$. These sunspots are independent across countries and over time. When a country switches from the bubbly to the bubbleless equilibrium, the old find that the value of the bubble they are holding collapses to zero and they suffer a loss. When a country switches from the bubbleless to the bubbly equilibrium, the old find themselves able to sell a useless object to the young and experience a windfall. The world starts with a fraction $\phi$ of all the countries having a bubble. Since this is the invariant distribution, the proportion of countries in each state is constant over time. The goal of this example is to show how the presence of bubbles makes countries fragile to shocks to expectations. In fact, it is tempting to think about this example as a model of financial fragility.

This change in assumptions implies a few minor adjustments in the argument of the previous subsection. If the $\mathrm{j}^{\text {th }}$ sunspot variable says NO BUBBLE, we have that 
$b_{t}^{j}=0$. If the $j^{\text {th }}$ sunspot variable says BUBBLE, we have then a stationary bubble very similar to the one in the previous section. Since there is a probability that the bubble bursts, condition (C1) now implies that:

$$
\left[1-\lambda+\lambda \cdot \frac{b^{H}}{b^{L}}\right] \cdot g^{\frac{1}{1-\alpha}} \cdot \phi \geq \pi^{\llcorner} \quad \text { and } \quad\left[1-\lambda+\lambda \cdot \frac{b^{L}}{b^{H}}\right] \cdot g^{\frac{1}{1-\alpha}} \cdot \phi \geq \pi^{H}
$$

Except for the knife-edge case in which both inequalities hold strictly, it follows from Equation (26) that:

$$
b^{L}=1 \quad b^{H}=\frac{\lambda}{\lambda+\frac{\pi^{H}}{\phi \cdot g^{\frac{1}{1-\alpha}}}-1}
$$

Conditional on remaining in the bubbly equilibrium, the behavior of the bubble is basically the same as in the previous example. Of course, now the bubble also bursts and reappears with some probability. Also, we can show that the dispersion of productivity required to sustain the bubbly equilibrium is higher here, since the probability of bursting makes the bubble less attractive.

The presence of the bubble opens the door for shocks to expectations to affect real variables such as investment and consumption. Conditional on not changing the equilibrium, the behavior of consumption and investment in countries with and without a bubble is the same as in the previous example. But now all countries go through periods in which they have a bubble and periods in which they do not. When the bubble bursts, consumption declines as the wealth of the old collapses and investment increases. In the aftermath of the bursting of the bubble, consumption increases in high productivity countries but declines in low productivity ones. When the bubble appears, consumption increases and investment declines. In 
the aftermath of the appearance of the bubble, consumption declines in high productivity countries but increases in low productivity ones.

An interesting finding relates to the interaction between shocks to productivity and shocks to expectations. Since countries tend to have a large bubble component in their wealth when productivity is low, shocks to expectations tend to have more extreme effects on macroeconomic aggregates and welfare during recessions. Conversely, during booms countries are less fragile or more resilient to shocks to expectations because the bubble component of wealth is smaller. Therefore, we find that shocks to productivity and expectations multiply the effects of each other and tend to increase the amplitude of economic fluctuations if they are positively correlated.

Although the model cannot predict the onset of expectations-driven crises, ${ }^{12}$ it still offers fresh insights into old problems. Consider for instance the popular view that countries should impose a Tobin tax or some sort of capital controls to reduce the probability of costly financial crises and help stabilize small open economies. The example presented here depicts a case in which financial fragility arises precisely as a result of impediments to asset trade. In the absence of these impediments, all world investment would be located in the high productivity countries. In such a world, there would be no room for shocks to expectations and their wealth effects. The theory therefore suggests the opposite view that in order to eliminate bubbles and the financial fragility that accompanies them one should not add frictions in financial markets, but remove them instead.

\footnotetext{
12 This would certainly be too much to ask from the model. After all, the model cannot predict the onset of productivity-driven crises either. To determine the equilibrium path of the world economy, we must specify a path for both productivity and expectations. Both variables are taken as given here and this is why I label them shocks.
} 


\section{Vulnerability to External Shocks}

Consider a world economy with two countries. North's productivity fluctuates between a high and a low state, i.e. $\pi_{t}^{\mathrm{N}} \in\left\{\pi^{\mathrm{L}}, \pi^{\mathrm{H}}\right\}$ with $\pi^{\mathrm{H}}>\pi^{\mathrm{L}}$; while South's is constant but low: $\pi^{\mathrm{S}}<\pi^{\mathrm{L}}$. As in previous examples, this productivity is known before investments are made, i.e. $E_{t}\left\{\pi_{t+1}^{N}\right\}=\pi_{t+1}^{N}$. In this world economy, all productivity fluctuations have their origin in North. The goal of this example is to show that the presence of bubbles makes low and middle-income countries particularly vulnerable to productivity fluctuations in rich countries.

If the North-South productivity gap is small, the unique equilibrium of this world economy is the bubbleless one. In this equilibrium, the world allocates half of its investment in North and the rest in South. As a result, we have that:

$$
\begin{aligned}
& g_{t}=\left(\alpha \cdot \frac{\pi_{t}^{N}+\pi^{S}}{2}\right)^{1-\alpha} \\
& \frac{R_{t}^{N}}{R_{t}^{S}}=\frac{\pi_{t}^{N}}{\pi^{S}}
\end{aligned}
$$

Equations (28) and (29) describe the evolution of world growth and the world distribution of consumption or wealth in the bubbleless equilibrium. The top panel of Figure 2 shows this evolution graphically. The world growth rate fluctuates as a result of productivity shocks in North. Since each country invests at home, North tends to suffer more from its own shocks than South.

If the North-South productivity gap is large, there is a bubbly equilibrium in which South has a stationary bubble defined by $b_{t}^{S}=1$ for all t. Assume South 
coordinates to this equilibrium with probability one. Then, all the investment is done in North and, as a result, we have that:

$$
\begin{aligned}
& g_{t}=\left(\alpha \cdot \frac{\pi_{t}^{N}}{2-\alpha}\right)^{1-\alpha} \\
& \frac{\mathrm{R}_{t}^{N}}{\mathrm{R}_{\mathrm{t}}^{S}}=\frac{2-\alpha}{\alpha}
\end{aligned}
$$

The middle panel of Figure 2 shows the evolution of the world growth rate and relative consumptions in the bubbly equilibrium. The presence of the bubble makes the world growth rate more sensitive to productivity shocks in North, since now these shocks not only raise the rate of return to North's investment but also the growth rate of South's bubble. The presence of the bubble also tends to synchronize economic fluctuations in North and South. In the bubbleless equilibrium, the return to each country portfolio depends more on the country's own productivity than in the productivity of the other country. In the bubbly equilibrium, the returns to both countries' portfolios depend only on North's productivity. As a result, the bubble generates a perfect correlation in country portfolios and wealth. Despite North having more volatile productivity than South, both countries experience the same volatility in their consumption and wealth.

If the North-South productivity gap is small, South is better off investing. If the gap is large, South is better off not investing and instead holding a bubble. If the gap is intermediate however, South might be better off investing when North's productivity is low, but might be better off holding a bubble when North's productivity is high. Is such behavior possible? The answer is 'almost'. If the North-South productivity gap is intermediate, there is a bubbly equilibrium in which South's bubble expands with an increase in North's productivity and contracts with a decrease. To see this, assume that South has a stationary bubble, i.e. $b_{t}^{S}=b^{H}$ if $\pi_{t}^{N}=\pi^{H}$ and $b_{t}^{S}=b^{L}$ if $\pi_{t}^{N}=\pi^{L}$. 
Assume also that the growth rate has four states, i.e. $g_{t}=g^{H H}$ if $\pi_{t}^{N}=\pi_{t+1}^{N}=\pi^{H}$, $g_{t}=g^{H L}$ if $\pi_{t}^{N}=\pi^{H}$ and $\pi_{t+1}^{N}=\pi^{L}, g_{t}=g^{L L}$ if $\pi_{t}^{N}=\pi_{t+1}^{N}=\pi^{\mathrm{L}}$ and $g_{t}=g^{H L}$ if $\pi_{t}^{N}=\pi^{\mathrm{L}}$ and $\pi_{\mathrm{t}+1}^{\mathrm{N}}=\pi^{\mathrm{H}}$ (this turns out to be the right guess, of course). With these definitions, condition (C1) implies that:

$$
\begin{aligned}
& (1-\lambda) \cdot g^{L L}+\lambda \cdot \frac{b^{L}}{b^{H}} \cdot g^{L H} \geq\left[(1-\lambda) \cdot\left(g^{L L}\right)^{\frac{-\alpha}{1-\alpha}}+\lambda \cdot\left(g^{L H}\right)^{\frac{-\alpha}{1-\alpha}}\right] \cdot \pi^{S} \text { and } \\
& (1-\lambda) \cdot g^{H H}+\lambda \cdot \frac{b^{H}}{b^{L}} \cdot g^{H L} \geq\left[(1-\lambda) \cdot\left(g^{H H}\right)^{\frac{-\alpha}{1-\alpha}}+\lambda \cdot\left(g^{H L}\right)^{\frac{-\alpha}{1-\alpha}}\right] \cdot \pi^{S}
\end{aligned}
$$

Except for the knife-edge case in which both inequalities are strict, it follows that:

$$
b^{\mathrm{L}}=\frac{g^{\mathrm{LH}} \cdot \lambda}{\left[(1-\lambda) \cdot\left(g^{\mathrm{LL}}\right)^{\frac{-\alpha}{1-\alpha}}+\lambda \cdot\left(g^{\mathrm{LH}}\right)^{-\alpha-\alpha}\right] \cdot \pi^{\mathrm{S}}-g^{\mathrm{LL}} \cdot(1-\lambda)} \quad \text { and } \quad b^{H}=1
$$

This bubble is similar to those found in previous examples. When North productivity is high, the bubble expands and reallocates investments from South to North. When North productivity is low, the bubble contracts and reallocates investments from North to South. Using condition (C2), we also find the following process for the growth rate as a function of the bubble:

$$
\begin{aligned}
& g^{H H}=\left(\alpha \cdot \frac{\pi^{H}}{2-\alpha}\right)^{1-\alpha}, g^{H L}=\left(\alpha \cdot \frac{\pi^{H}}{2-\alpha \cdot b^{L}}\right)^{1-\alpha}, g^{L L}=\left(\alpha \cdot \frac{\pi^{H}+\left(1-b^{L}\right) \cdot \pi^{L}}{2-\alpha \cdot b^{L}}\right)^{1-\alpha} \\
& \text { and } g^{\mathrm{LH}}=\left(\alpha \cdot \frac{\pi^{H}+\left(1-b^{L}\right) \cdot \pi^{L}}{2-\alpha}\right)^{1-\alpha}
\end{aligned}
$$


where I have used the finding that $b^{H}=1$. Equations (33) and (34) implicitly define the growth process and the behavior of the bubble. In general, these equations cannot be solved analytically, although it is quite straightforward to solve the system numerically.

The bottom panel of Figure 2 shows the evolution of the world growth rate and the world distribution of consumption in this equilibrium. Conditional on being in normal times (i.e. periods in which a country does not transition from one state to the other), South experiences a smoother consumption process than North. During a boom, South holds the bubble to take advantage of the high productivity of North. During a recession, South shifts its portfolio towards investment to moderate the fall in its return. But, as in previous examples, bubbles generate potentially large wealth effects during the transitions. In particular, the onset of a recession leads to a collapse in the bubble while the beginning of a boom leads to an expansion in the bubble. On impact, recessions and booms are felt much more strongly in South even if they have their origin in North. After the dust clears, changes in North productivity affect relatively more North than South. This world economy therefore illustrates how bubbles create a channel for small productivity shocks in North to create sharp changes in asset prices in South. These movements in asset prices in turn generate large effects on consumption, wealth and welfare.

This example also provides a new perspective on the connection between economic reforms and vulnerability to external crises. The key observation is that successful economic reforms in South lead to a progressive reduction in the NorthSouth productivity gap. Assume initially that this gap is large and South, perhaps with some encouragement from North, decides to implement reforms. In their first stage, these reforms might be successful at raising South's productivity, but they have no impact on its consumption or welfare since South still prefers to hold the bubble rather than to invest. Assume that, despite this apparent lack of success, South decides to pursue reforms even further until the productivity gap becomes 
intermediate. In this second stage, South notices some convergence towards North's average levels of consumption and wealth. But at the same time, South finds itself more vulnerable to North shocks. Small drops in North productivity create sharp financial crises. Small increases in North productivity lead to asset price booms. The reforms have made consumption higher on average, but much more volatile. Assume that South reacts to this by further implementing reforms until the productivity gap is small. At this point, South finally enjoys high and stable consumption. The bubble is gone, and so are the wealth effects that are at the root of the sharp crises and booms.

The bubble also determines the distributive effects of reforms. Whenever we reach stage two of the reforms, a conflict arises between the young and the old. Successful economic reforms make investment more attractive, reducing the demand for the bubble and leading to its contraction or bursting. This leads to a fall in consumption and the welfare of the old. After this initial decline in wealth and consumption, all future generations in South (and North) are better off as a result of the economic reforms. To the extent hath transferring resources across different groups is costly, the presence of a bubble makes more difficult to reach a consensus on the need to implement reforms. The key reason is that these economic reforms harm the owners of the bubble if they are successful.

\section{Contagion}

Consider a world economy with three countries, West, East and South; with productivities equal to $\pi^{\mathrm{W}}>\pi^{\mathrm{E}}>\pi^{\mathrm{S}} \approx 0$, respectively. With this assumption, we already know that West cannot have a bubble and that South can. Whether East can have a bubble or not depends on parameter values. I assume that South uses a sunspot variable to coordinate to a given equilibrium. This sunspot variable has two states: BUBBLE and NO BUBBLE; and the probability to transition from one state to the 
other is given by $\lambda$. When the bubble bursts in South, consumption and wealth drop to zero there. The goal of this example is to study how these expectations-driven financial crises in South are propagated to West and East.

The structure of this example is very similar to that of the previous one, with financial crises in South taking up the role of productivity shocks in North. If the WestEast productivity gap is small, East cannot have a bubble and the equilibrium is given by:

$$
g_{t}=\left(\alpha \cdot \frac{\pi^{W}+\pi^{E}}{3-\alpha \cdot b_{t+1}^{S}}\right)^{1-\alpha}
$$

$$
R_{t}^{j}=g_{t}^{\frac{-\alpha}{1-\alpha}} \cdot \pi^{j} \text { for } j=W, E \quad \text { and } \quad R_{t}^{S}= \begin{cases}g_{t} & \text { if } b_{t}^{S}=b_{t+1}^{S}=1 \\ -\infty & \text { if } b_{t}^{S}=1 \text { and } b_{t+1}^{S}=0 \\ 0 & \text { if } b_{t}^{S}=b_{t+1}^{S}=0 \\ \infty & \text { if } b_{t}^{S}=0 \text { and } b_{t+1}^{S}=1\end{cases}
$$

The world growth rate fluctuates with South's bubble. Increases in the bubble transfer resources to West and East that are invested more efficiently, raising the world growth rate. When the bubble bursts, these resources return to South where they are invested with very low efficiency (essentially wasted since $\pi^{S} \approx 0$ ), lowering the world growth rate. Through this channel, movements in the bubble affect the world growth rate and the distribution of consumption. When the bubble bursts, there is a proportional increase in the return to the portfolios of both North and South, as the lower growth rate implies a slower decline in the price of investment goods. Hence, movements in the bubble do not affect their relative consumption or wealth, i.e. $\frac{C_{t}^{W}}{C_{t}^{E}}=\frac{\pi^{W}}{\pi^{E}}$. 
If the West-East productivity gap is large, East can have a stationary bubble defined by $b_{t}^{S}=1$ for all t. Assume East coordinates to this bubble with probability one. Then, we have that:

$$
g_{t}=\left(\alpha \cdot \frac{\pi^{W}}{3-\alpha \cdot\left(1+b_{t+1}^{S}\right)}\right)^{1-\alpha}
$$

$$
R_{t}^{W}=g_{t}^{\frac{-\alpha}{1-\alpha}} \cdot \pi^{W}, \quad R_{t}^{E}=g_{t} \quad \text { and } \quad R_{t}^{S}= \begin{cases}g_{t} & \text { if } b_{t}^{S}=b_{t+1}^{S}=1 \\ -\infty & \text { if } b_{t}^{S}=1 \text { and } b_{t+1}^{S}=0 \\ 0 & \text { if } b_{t}^{S}=b_{t+1}^{S}=0 \\ \infty & \text { if } b_{t}^{S}=0 \text { and } b_{t+1}^{S}=1\end{cases}
$$

Once again, the world growth rate fluctuates with South's bubble for exactly the same reasons it did in the bubbleless equilibrium. But now the shock is propagated differently to East and West. While the bursting of the bubble still raises the return to West's portfolio, it now reduces the return to East's because the fall in the world growth rate decreases the return to East's bubble. When East has a bubble, shocks to expectations in South have a larger effect on East than on West, i.e.

$$
\frac{C_{t}^{W}}{C_{t}^{E}}=\frac{\pi^{W}}{g_{t}^{\frac{1}{1-\alpha}}} \text {. }
$$

The most interesting case is the one in which the productivity gap is intermediate. Then East has a bubble that contracts when South's bubble bursts and expands when South's bubble re-appears. To see this, use condition (C1) to find that Equations (32) and (33) apply now to East's bubble, provided that we replace $\pi^{\mathrm{S}}$ by $\pi^{\mathrm{E}}$ and use the superscripts " $\mathrm{H}$ " and " $\mathrm{L}$ " to indicate $b_{t}^{S}=1$ and $b_{t}^{S}=0$, respectively. Moreover, we can also use condition (C2) to find that: 


$$
\begin{aligned}
& g^{\mathrm{HH}}=\left(\alpha \cdot \frac{\pi^{\mathrm{W}}}{3-\alpha \cdot 2}\right)^{1-\alpha}, g^{\mathrm{HL}}=\left(\alpha \cdot \frac{\pi^{\mathrm{W}}}{3-\alpha \cdot b^{\mathrm{L}}}\right)^{1-\alpha}, g^{\mathrm{LL}}=\left(\alpha \cdot \frac{\pi^{\mathrm{W}}+\left(1-b^{\mathrm{L}}\right) \cdot \pi^{\mathrm{E}}}{3-\alpha \cdot b^{\mathrm{L}}}\right)^{1-\alpha} \\
& \text { and } g^{\mathrm{LH}}=\left(\alpha \cdot \frac{\pi^{\mathrm{W}}+\left(1-\mathrm{b}^{\mathrm{L}}\right) \cdot \pi^{\mathrm{E}}}{3-\alpha \cdot 2}\right)^{1-\alpha}
\end{aligned}
$$

where I have used the finding that $b^{H}=1$. Equations (33) and (39) implicitly define the growth process and the bubble. The behavior of East's bubble is analogous to that described in the previous example. This reinforces the message that middle-income countries are especially vulnerable to external shocks, regardless of whether the origin of these shocks is a drop of productivity in high productivity countries or a coordination failure in low productivity ones.

This example also gives rise to a phenomenon that resembles the "contagion" of financial crises that we sometimes observe in the real world. Note that movements in South's bubble generate positively correlated movements in East's bubble. The key insight of this example is that bubbles are complements. That is, bubbles elsewhere in the world raise the world growth rate and make it more likely that a bubble appears at home. If the West-East productivity gap is intermediate, a large bubble in East can be supported if and only if there is a bubble in South. Under these circumstances, if South's bubble bursts East's bubble sharply contracts. This positive correlation in the bubbles of South and East happens even though there are few direct linkages between them. Naturally, there are no capital flows between East and South since I have ruled them out from the start. Moreover, the example can also be constructed in such a way that there is no commodity trade between these countries either. ${ }^{13}$

\footnotetext{
${ }^{13}$ The patterns of trade in this world are straightforward. When South has a bubble, East and South are exporters of L-products, while West is an exporter of K-products. As a result East and South do not trade with each other. When South does not have a bubble, South is still an exporter of L-products, while North is still an exporter of K-products. Whether East remains an exporter of L-products or becomes now an exporter of K-products depends on parameter values. For instance, if $\alpha$ is large the demand for Lproducts is strong enough that East remains an exporter of L-products. In this case, East and South never trade.
} 


\section{Conclusion}

The theory developed here provides a new view of asset price bubbles as a market-generated device to facilitate international capital flows in the presence of frictions in international financial markets. The central insight is that bubbles tend to appear and expand in countries where productivity is low relative to the rest of the world. These bubbles absorb local savings, eliminating inefficient investments and liberating resources that are in part used to invest in high productivity countries. This improves the world allocation of investment and reduces rate-of-return differentials across countries. As a result, bubbles allow the world economy to operate at a higher level of efficiency.

This theory of asset price bubbles extends and complements the standard productivity-based view of economic growth, providing it with the potential to account for a wide range of real world phenomenae that had proved quite difficult to model before. With the help of some examples, I have derived a number of suggestive and somewhat surprising results regarding the interaction between bubbles and productivity and how this interaction shapes the growth process. While some of these results are likely to withstand realistic extensions of the theory, others will certainly not. I regard the model proposed here as a first step towards a better understanding of the connection between asset price bubbles, international capital flows and economic growth. 


\section{References}

Abel, A.B., N.G. Mankiw, L.H. Summers and R.J. Zeckhauser [1989], "Assessing Dynamic Efficiency: Theory and Evidence," The Review of Economic Studies, 56, 1, $1-19$.

Acemoglu, D. and J. Ventura [2002], "The World Income Distribution," Quarterly Journal of Economics, CXVII, 2, 659-694.

Helpman, E. and P.R. Krugman, Market Structure and Foreign Trade, MIT Press.

Howitt, P. [2002], "Endogenous Growth and Cross-country Income Differences," American Economic Review, 90, 829-846.

Kraay, A., N. Loayza, L. Servén and J. Ventura [2000], "Country Portfolios," NBER working paper W7795.

Olivier, Jaques [2000], "Growth-Enhancing Bubbles," International Economic Review, 41(1), 133-151.

Samuelson, P.A. [1948], "International Trade and The Equalization of Factor Prices," Economic Journal, LVIII, 163-84.

Samuelson, P.A. [1958], "An Exact Consumption-Loan Model of Interest with or Without the Social Contrivance of Money," Journal of Political Economy, 66, pp. 467482.

Tirole, J. [1985], "Asset Bubbles and Overlapping Generations," Econometrica, 53, pp. 1499-1528.

Ventura, J. [1997], "Growth and Interdependence," Quarterly Journal of Economics, CXII, 1, 57-84.

Ventura, J. [2002], "Economic Growth with Bubbles," MIT, work in progress. 
Figure 1

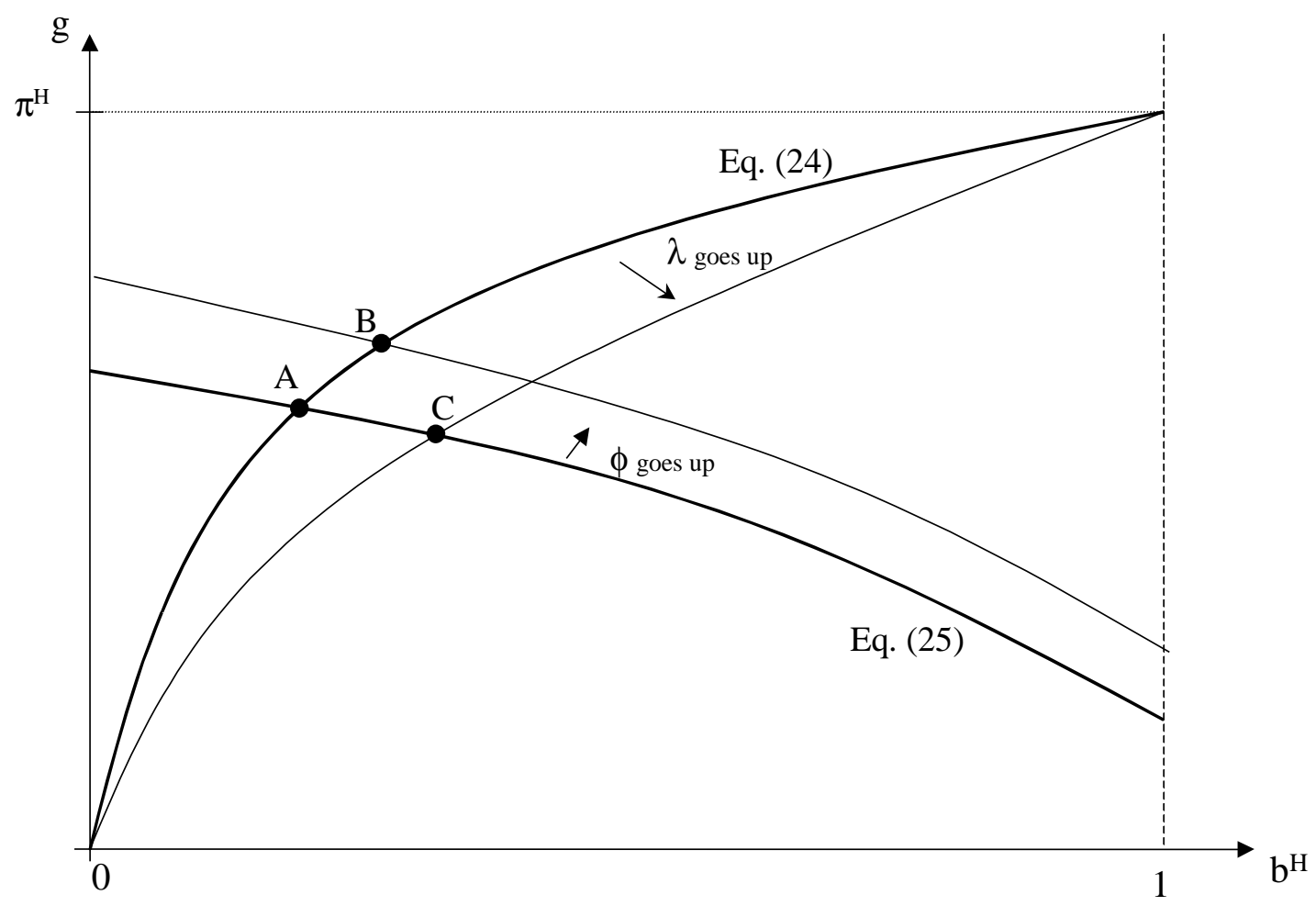


Figure 2

Small Gap

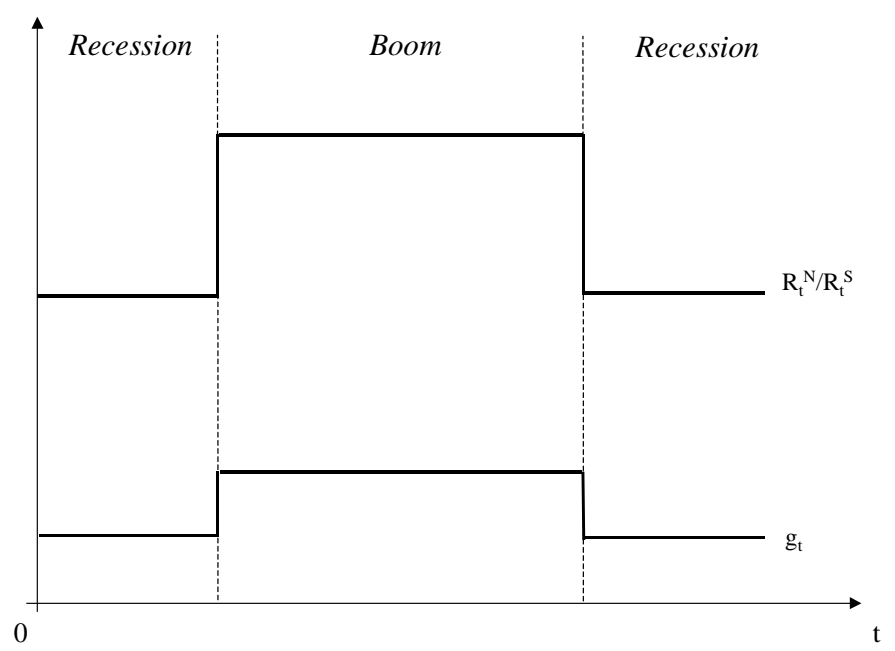

Large Gap

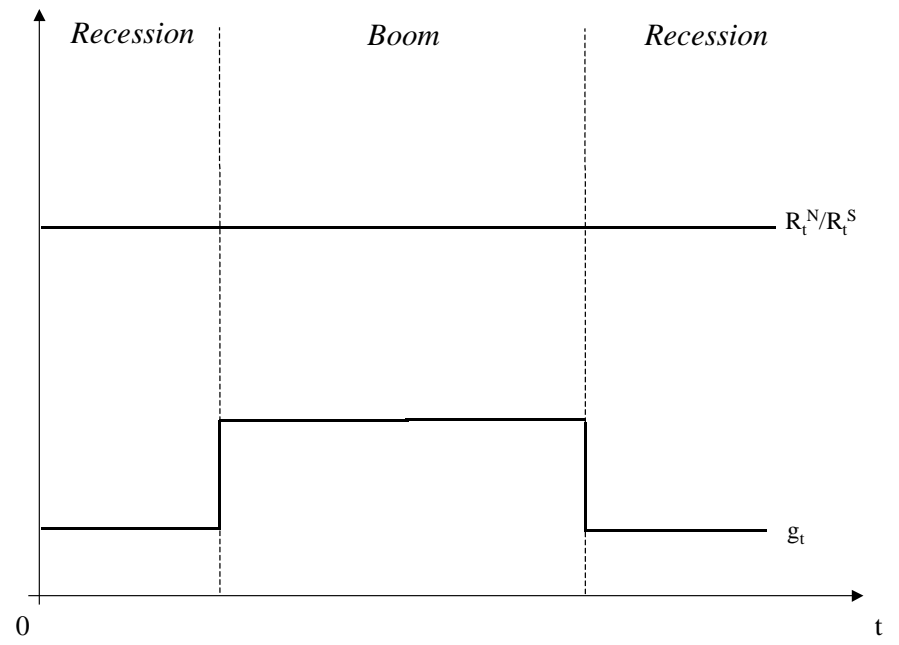

Intermediate Gap

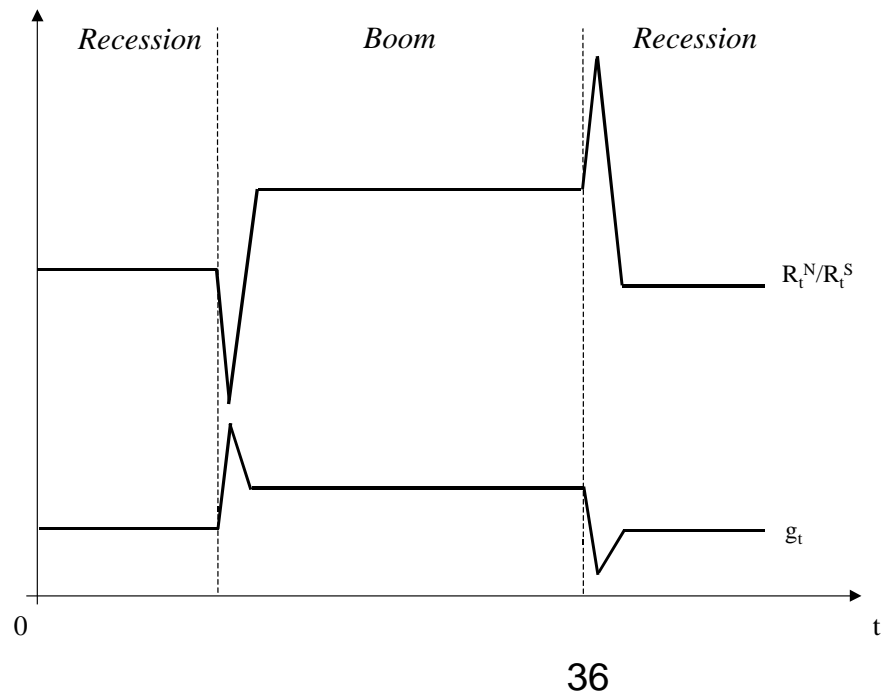

